\title{
Very slow creep tests on rock samples
}

\author{
P.Bérest, J.F. Béraud, M. Bourcier, A. Dimanov \& H. Gharbi \\ LMS, Ecole Polytechnique, Palaiseau, France
}

B. Brouard

Brouard Consulting, Paris, France

K. DeVries

RESPEC, Rapid City, South Dakota, USA

\author{
D. Tribout \\ Compagnie des Salins du Midi et Salines de l'Est, Varangéville, France
}

\begin{abstract}
Twelve years ago, creep tests at very low deviatoric stress were performed on an Etrez salt sample in the Varangéville Mine. Recently, a new testing campaign was performed on various salt samples to gain further insight on salt behavior. Creep tests are performed under a $0.1 \mathrm{MPa}$ uniaxial loading on rock-salt samples from the Varangéville and Avery Island Mines and under a $0.24 \mathrm{MPa}$ uniaxial loading on a crushedsalt sample. To minimize the effects of temperature variations, testing devices were placed in an underground mine room, where temperature fluctuations are of the order of one-hundredth of a degree Celsius. The mechanical loading is provided by dead weights. The deformations were measured through special displacement sensors with a resolution of $1 / 80 \mu \mathrm{m}$. A typical steady-state strain rate reached after 6 months is $-2.4 \times 10^{-12}$ $\mathrm{s}^{-1}$. The influence of air hygrometry, which is approximately $74 \% \mathrm{RH}$ in the mine, is smaller than expected.
\end{abstract}

\section{INTRODUCTION}

\subsection{Norton-Hoff law}

The mechanical behavior of salt has given rise to abundant literature. When a constant mechanical load is applied to a salt sample, most authors observe: a steady-state strain rate is reached after some time, it is a nonlinear function of the applied stress, it is sensitive to temperature, and no volume change is observed. The main features of such a steady-state behavior are captured by the Norton-Hoff law, or $d \varepsilon^{s s}(\sigma, T) / d t=A \exp (-Q / R T) \sigma^{n}$. Typical values for the constants $n$ and $Q / R$ range from 3 to 6 and from 3,000 to $10,000 \mathrm{~K}$, respectively. The steady-state strain rate $\left(d \varepsilon^{s s} / d t\right)$ is typically about $10^{-10} \mathrm{~s}^{-1}$ for a deviatoric stress $(\sigma)$ of $10 \mathrm{MPa}$ and temperature $(T)$ of $300 \mathrm{~K}$. This rate is relatively slow, and during most laboratory tests, the applied stress is larger than $10 \mathrm{MPa}$.

The generalized formulation of the Norton-Hoff law is given by $d \varepsilon_{i j}^{s s} / d t=3 A^{*}\left(J_{2}\right)^{(n-1) / 2} s_{i j} / 2$, where $A^{*}=A \exp (-Q / R T)$ and $s_{i j}=\sigma_{i j}-\sigma_{k k} \delta_{i j}$ is the deviatoric stress tensor whose second invariant is $J_{2}=s_{i j} s_{j i} / 2$. For an idealized spherical cavern subjected to a constant geostatic pressure of $P_{\infty}$ and cavern (constant) pressure of $P_{c}$, the steady-state creep closure rate and second invariant can be expressed as:

$\dot{V} /\left.V\right|_{s s} ^{N H}=-3 A^{*}\left[3\left(P_{\infty}-P_{c}\right) / 2 n\right]^{n} / 2$ $\left.\sqrt{3 J_{2}}\right|_{s s} ^{N H}=3\left(P_{\infty}-P_{c}\right)(a / r)^{3 / n} / 2 n$

where $r$ is the distance to cavern center and $a$ is radius of the cavern. For an 800-meter-deep cavern, assuming $n=4$ and $P_{\infty}-P_{c}=8 \mathrm{MPa}$, the largest value of the second invariant of the deviatoric stress is reached at the cavern wall $(r=a)$ where $\left(3 J_{2}\right)^{1 / 2}=$ $3 \mathrm{MPa}$. In other words, cavern behavior is extrapolated from tests performed in a stress range which is not the stress range actually observed at the vicinity of a cavern.

\subsection{Deformation mechanism}

Langer (1984) stated that reliable extrapolation of the creep equations at low deformation rates can be carried out only on the basis of deformation mechanisms. The micromechanisms that govern salt creep have been discussed by Munson \& Dawson (1984), Langer (1984), or Blum \& Fleischman (1988). A deformation-mechanism map (adapted from Munson \& Dawson 1984) is presented in Figure 1 (the star on Fig. 1 represents testing conditions during the tests described below).

The $0-120^{\circ} \mathrm{C}$ by $5-20 \mathrm{MPa}$ rectangle in Figure 1 is the domain inside which most laboratory tests are performed. In fact, the micromechanisms that govern creep in the $0-5 \mathrm{MPa}$ domain, which is of primary interest, are unknown. In other words, prediction of the mechanical behavior of salt in this domain is based on extrapolation of purely empirical 
data and cannot be supported by theoretical consideration.

However, Spiers et al. (1990) and Uraï \& Spiers (2007) observed that in the low-stress domain, pressure-solution creep, an important deformation mechanism of most rocks in the earth's crust, is especially rapid in the case of rock salt. Theoretical findings strongly suggest that, for this mechanism, the relation between deviatoric stress and strain rate is linear. Furthermore, a nearly linear dependence between strain rate and deviatoric stress also is reported in several works concerned with low stress plastic deformation of various polycrystalline and single crystalline metals and oxide alloys (Kumar et al. 2007, 2009) and, in particular, rock-salt single crystals (Banerdt \& Sammis 1985), in which no pressure-solution creep can take place. This behavior was attributed to the controversial Harper-Dorn creep regime (Harper \& Dorn 1957). The latter is dominated supposedly by dislocation glide, but unlike dislocation slip and climb regimes (power law creep), it is operating at low and constant dislocation density (Wang \& Nieh, 1995).

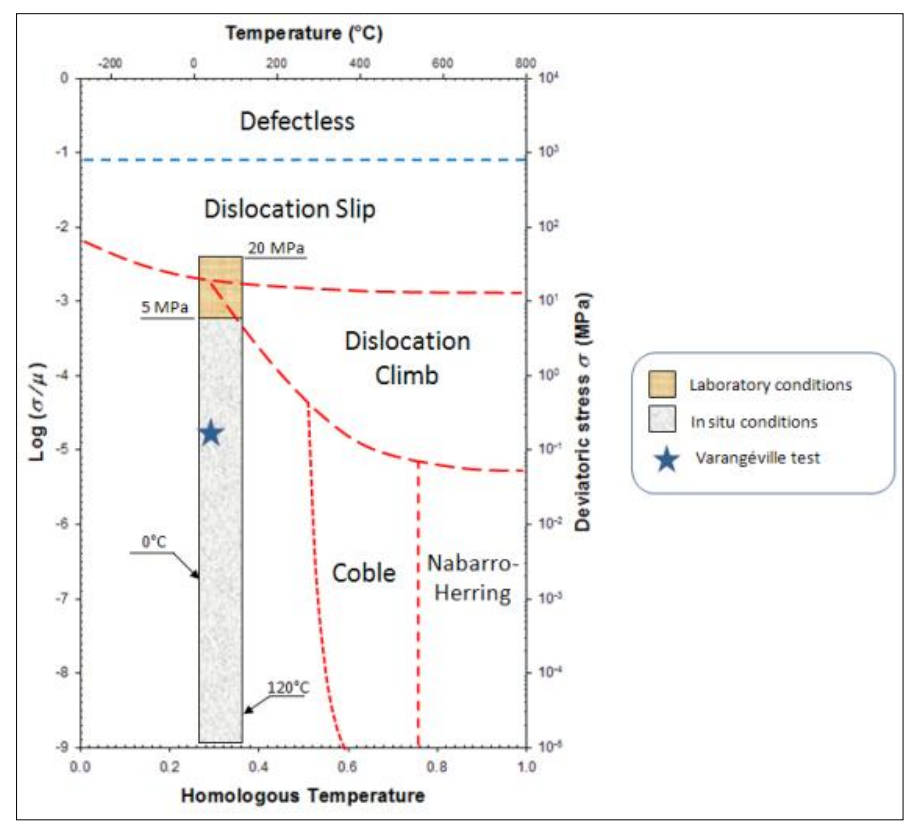

Figure 1. Mechanism map (after Munson \& Dawson 1984).

\subsection{Consequences for the behavior of a cavern}

The following simplistic model (a "bilinear" function in the $\log d \varepsilon^{s s} / d t-\log \sigma$ plot) captures the main features of such a behavior:

$\sigma>S: \quad \dot{\varepsilon}^{S S}=A^{*} \sigma^{n} \quad \sigma<S: \quad \dot{\varepsilon}^{S S}=A^{*} S^{n-1} \sigma$

where $S$ is the threshold separating the low-stress and high-stress domains. In other words, when deviatoric stress is sufficiently large, the standard Norton-Hoff law $(n \neq 1)$ holds; when the deviatoric stress is small, the Newtonian law $(n=1)$ for viscous fluids holds. Consider again an idealized spherical cavern and steady-state creep closure: when the cavern is deep enough, the rock mass is divided into two zones. In the zone closest to the cavern, deviatoric stresses are relatively large. Farther from the cavern, deviatoric stresses are relatively small. The steady-state cavern closure rate of the bilinear model can be computed easily (Bérest et al. 2009):

$\dot{V} /\left.V\right|_{S S} ^{B L}=\dot{V} / V_{S S}^{N H} \times\left[1+2(n-1) S / 3\left(P_{\infty}-P_{c}\right)\right]^{n}$

If we assume $n=4, S=4 \mathrm{MPa}$ (these figures are purely indicative), and $P_{\infty}-P_{c}=8 \mathrm{MPa}$, then $\dot{V} /\left.V\right|_{S S} ^{B L}=17 \dot{V} /\left.V\right|_{S S} ^{N H}$. Thus even when "reasonable" values of $n$ and $S$ are selected, the creep closure rate is significantly faster when the Norton-Hoff creep law is modified slightly to take into account the effect of small deviatoric stresses. Possible field evidences of such a "modified" Norton-Hoff behavior were discussed by Campos de Orellana (1998), Breunesse et al. (2003), Uraï \& Spiers (2007), and Bérest et al. (2009). Such a behavior is taken into account in the so-called modified Lubby2 law (Rokhar et al. 2011).

\section{PROBLEMS RAISED BY SLOW-RATE CREEP TESTS}

Small strain rates $\left(-10^{-14}\right.$ to $\left.-10^{-11} \mathrm{~s}^{-1}\right)$ have not been investigated widely in the laboratory. Hunsche (1988) describes the measurement of creep in rock salt at small strain rates using a special testing device. The test lasted approximately 1 week, during which a strain rate of $-7 \times 10^{-12} \mathrm{~s}^{-1}$ was "the lowest reliably determined deformation rate" (Hunsche 1988). The limited available literature probably is inherent to the particular problems raised by longterm, slow-rate creep tests, as noted below.

1 When the creep rate is $-10^{-12} \mathrm{~s}^{-1}$, a test lasting 12 days results in a cumulated strain $(\varepsilon)$ of $-10^{-7}$. The thermal expansion coefficient $(\alpha)$ of salt is $4 \times 10^{-5} /{ }^{\circ} \mathrm{C}$ - and temperature variations $(\Delta T)$ of a couple of degrees Celsius will generate thermoelastic deformations which are larger than the signal to be measured (i.e. sample average deformation originated by creep proper) in many cases. The same can be said of small hygrometric variations (Horseman 1988, Hunsche \& Schultze 1996, 2002).

2 Slow creep rates are obtained when small mechanical loadings are applied. Most creep test devices are designed to operate in the deviatoric stress range of 5-20 MPa, and stress control usually is poor when the applied stress is smaller than 1 MPa. 
3 Creep rate is computed by comparing the strains $\varepsilon_{1}$, and $\varepsilon_{2}$ measured at two different times, $t_{1}$ and $t_{2}$, where $d \varepsilon / d t=\left(\varepsilon_{2}-\varepsilon_{1}\right) /\left(t_{2}-t_{1}\right)$. When, for instance, $d \varepsilon / d t=10^{-12} \mathrm{~s}^{-1}$ and $t_{2}-t_{1}=10^{6} \mathrm{~s}$, then $\varepsilon_{2}-\varepsilon_{1}=10^{-7}$. Therefore, a reasonable assessment of daily strain rate demands that strain be measured with an accuracy of $10^{-8}$.

In other words, accurate long-term creep tests are possible only when: (1) there is very accurate measurement of sample length change, (2) when the applied load remains constant, and (3) when the temperature and hygrometry experience very small changes. Such tests were performed in an underground mine to take advantage of very stable temperature using an accurate sensor and dead weight loading. A first series of tests were performed in 1997-1998 on an Etrez salt sample (Bérest et al. 2005). During the first stage of the test, the specimen was subjected to an axial stress of $0.108 \mathrm{MPa}$ and after 1 year, the creep rate was $-1.4 \times 10^{-12} \mathrm{~s}^{-1}$ (Fig. 2). Next, loading was decreased to $0.076 \mathrm{MPa}$, leading to rapid axial expansion followed by a long period of time during which delayed axial expansion ("inverse creep") occurred.

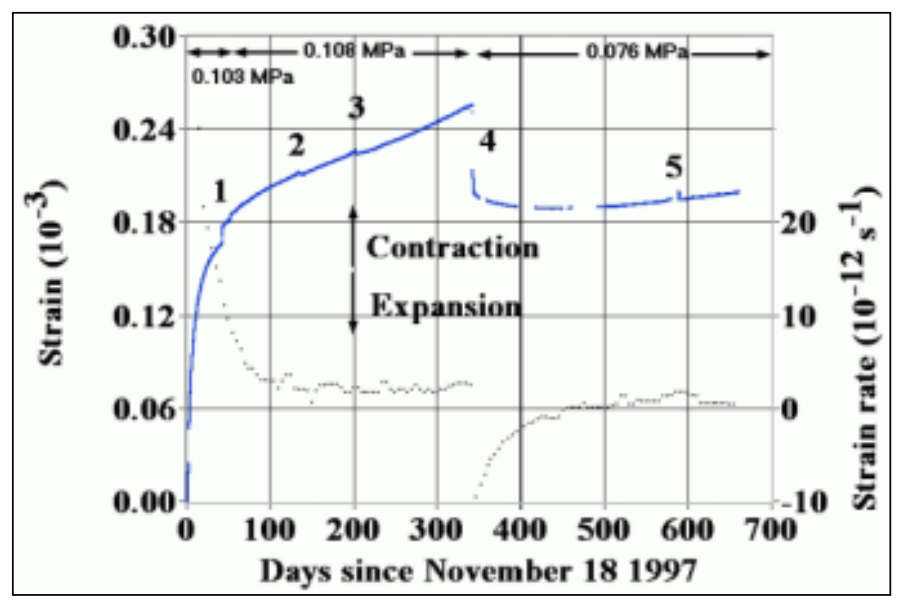

Figure 2. A 2-year-long creep test performed on a sample of Etrez salt.

A second series of tests are currently being performed. A description of the testing system, test conditions, and preliminary results are provided below.

\section{DESCRIPTION OF THE TESTING SYSTEM}

\subsection{Testing device, mechanical loading}

Uniaxial creep tests are being performed on cylindrical salt samples, $D=70 \mathrm{~mm}, H=140 \mathrm{~mm}$. The sample is set between two duralumin plates (Fig. 3). Dead weights are set on the lower part of a rigid frame. The frame weight is transmitted to the upper duralumin plate through a small metallic ball. The applied stress is calculated by dividing the overall weight of the steel frame by the initial cross section of the salt cylinder. The range of stresses that can be applied to a sample is 0.05 to $1 \mathrm{MPa}$. Such a device was emplaced in the mine on October 10, 2010, and a second device was emplaced on July 10, 2011.

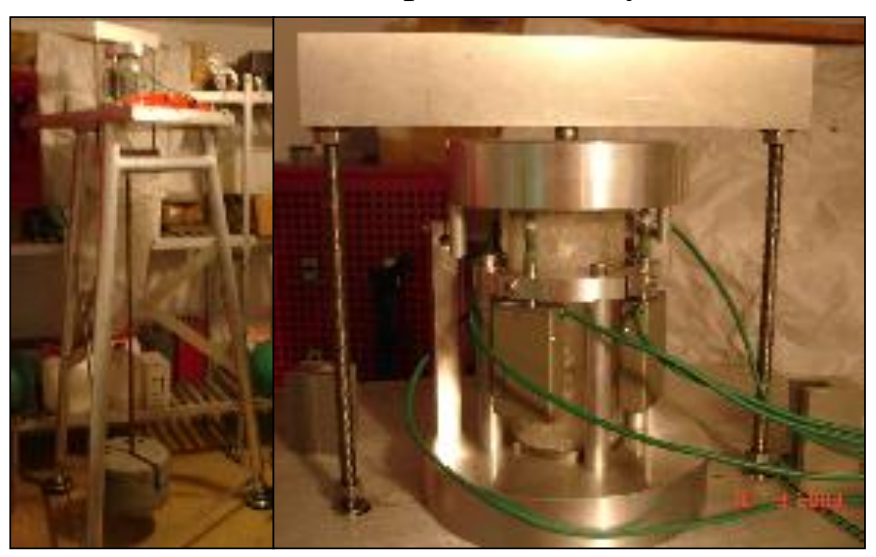

Figure 3. Testing device and salt sample below the upper plate.

\subsection{Sensors}

During a test, four (C1 to $\mathrm{C} 4)$ high-resolution displacement sensors (Solartron linear encoders) are positioned in two vertical planes at $90^{\circ}$ angles (Fig. 4). Their accuracy is $0.5 \mu \mathrm{m}$ and their resolution is $0.0125 \mu \mathrm{m}(1 / 80 \mu \mathrm{m})$. They allow both the relative rotation and the vertical displacement of the upper plate to be measured and provide some redundancy. In addition to the four vertical displacement sensors, two additional sensors measure the horizontal displacements (C5 and C6) generated by a possible sample torsion.
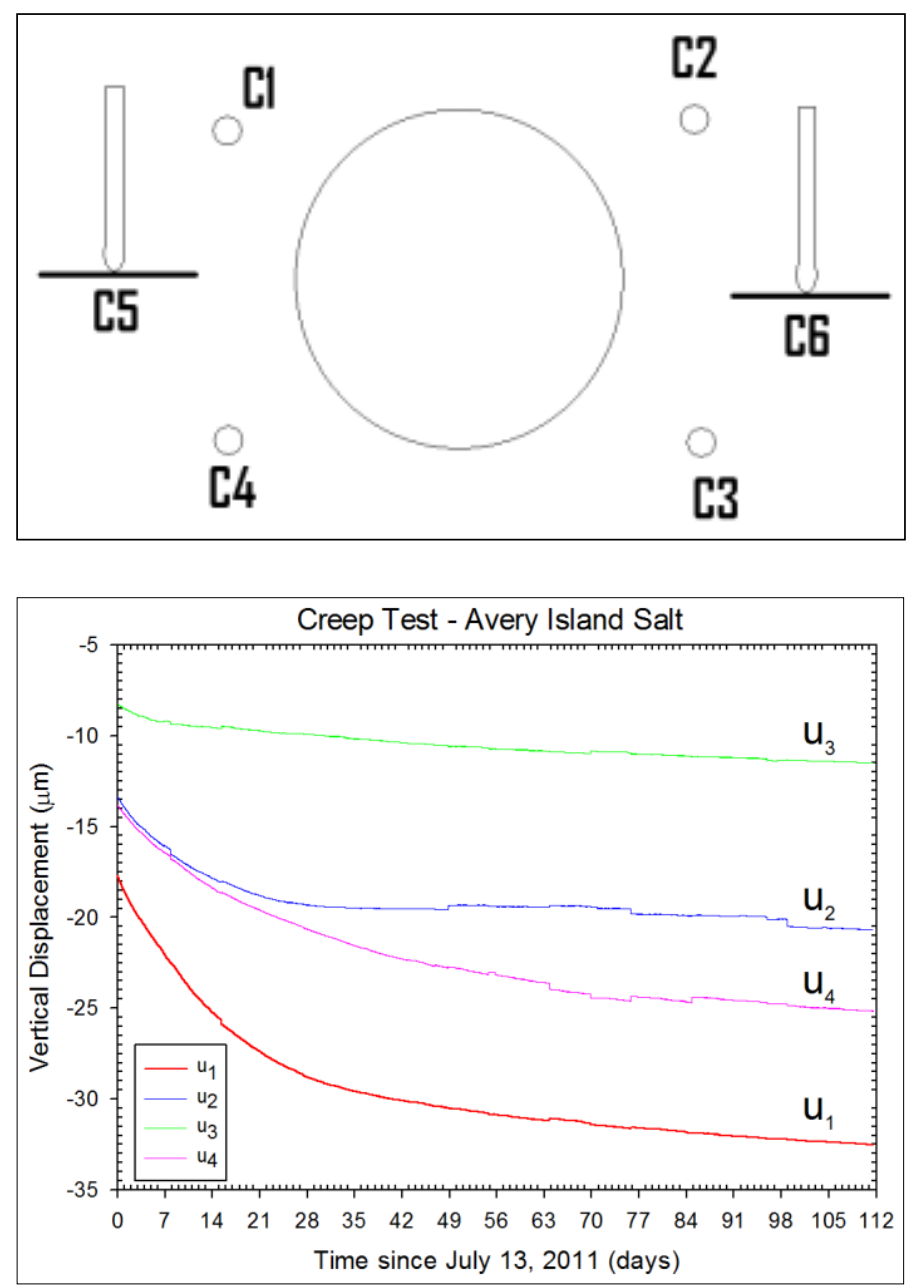
Figure 4. Vertical displacements measured by the four sensors.

\subsection{Rotation of the upper plate}

An example of plate rotation measured by the apparatus is provided in Figure 4. The displacements $u_{1}$, $u_{2}, u_{3}$, and $u_{4}$, of the four vertical sensors were measured during an 8-week-long period at the beginning of a test performed on an Avery Island salt sample. It can be observed that $u_{2} \approx u_{4} \approx\left(u_{1}+u_{3}\right) / 2$, proving that the four measured displacements are consistent and strongly suggesting that the upper plate is rotating along the $2-4$ horizontal axis.

\section{TEMPERATURE AND HYGROMETRY}

\subsection{Temperature fluctuations}

The temperature changes during a long-term isothermal creep test should be as small as possible to minimize measurement error. For this reason, the tests were performed in a deep underground room, where temperature is much more constant than in any surface facility. With the kind support of the Compagnie des Salins du Midi et Salines de 1'Est, tests were performed at the dead end of a 700-mlong, 160-m-deep gallery of the Varangéville (France) salt mine (Fig. 5). This gallery is remote from the area of present salt extraction.

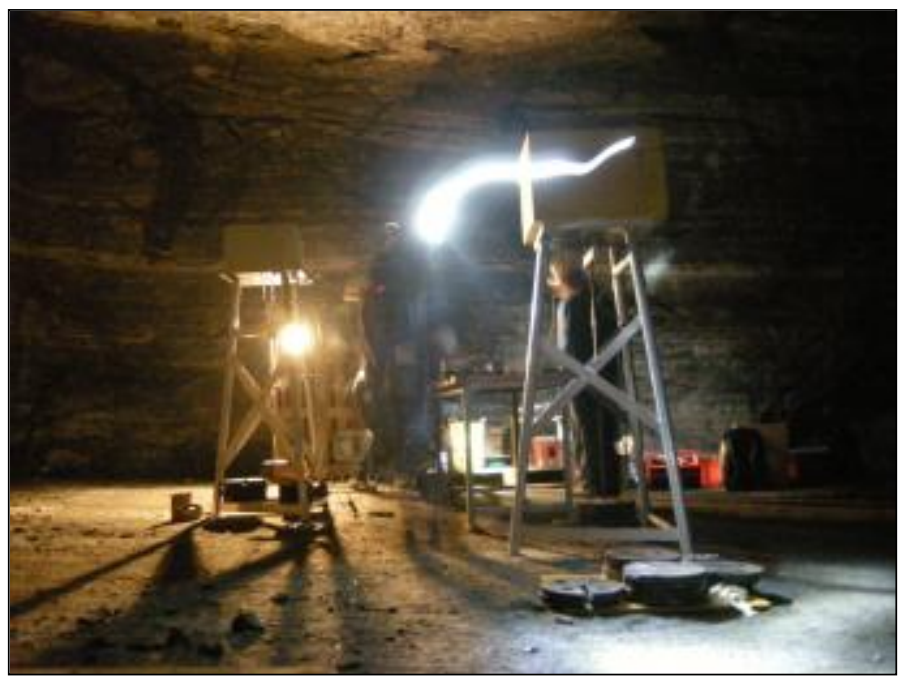

Figure 5. The testing devices at the dead-end of the gallery.

Gallery temperature must be measured precisely enough to allow correction of the raw strain data for thermoelastic strains. Temperature is measured by platinum sensors whose resolution is one thousandth of a degree Celsius; however, their accuracy is not better than $0.5^{\circ} \mathrm{C}$.

Temperature and hygrometry evolutions during the October 2010 to July 2011 period are illustrated in Figure 6. Large temperature changes are visible when members of the staff are working in the gallery; e.g. 18-20 October 2010 (Days 0 to 2), 30 November 2010 (Day 43), 18 February 2011 (Day
123), and 4-6 July 2011 (Days 259-261). A slow temperature decrease of about $-0.05^{\circ} \mathrm{C} / \mathrm{yr}$ can be observed during the winter. The resulting sample contraction rate, estimated by $\alpha d T / d t=-6 \times 10^{-14} / \mathrm{s}$, should not lead to significant misinterpretation of the test results. More erratic daily temperature changes also can be observed. They are slightly correlated to atmospheric pressure changes and are believed to be generated mainly by changes in the temperature and flow rate of the ventilation air.

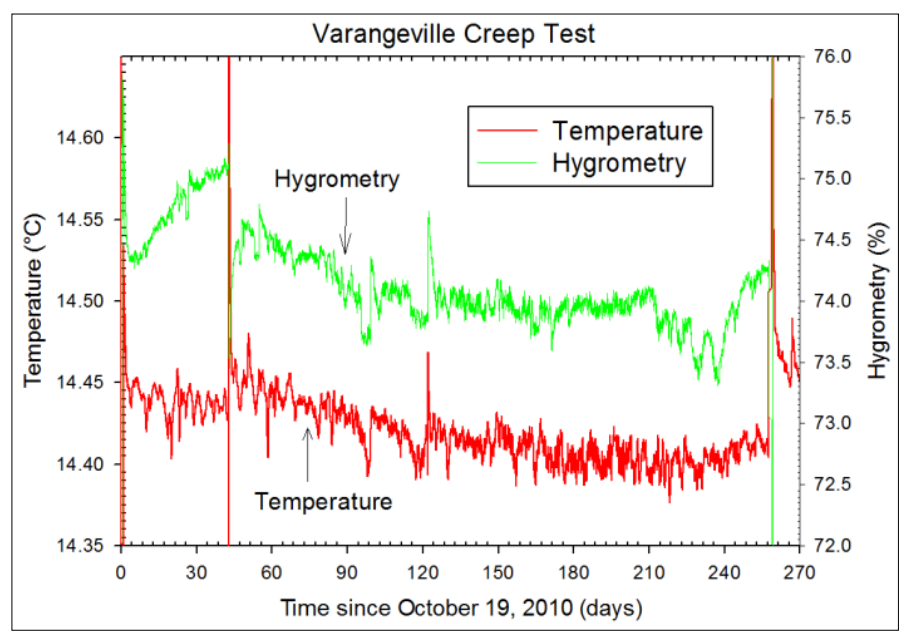

Figure 6. Temperature and hygrometry of the gallery air from day 1 to day 260 .

In fact, when the new series of tests began (October 2010), it was soon noticed that both temperature and hygrometry in the gallery had changed since the 1997-1998 campaign. The average temperature during the fall 2010 and winter 2011 was $14.4^{\circ} \mathrm{C}$, compared to $13.5^{\circ} \mathrm{C}$ observed during the $1197-1998$ campaign. The accuracy of the Pt1000 temperature gauge being used is relatively poor but its resolution is high. In July 2011 (Day 260), a second Pt1000 sensor was implemented in the gallery (Fig. 7). The recorded temperature of the second sensor was about $14.2^{\circ} \mathrm{C}$, or $0.2^{\circ} \mathrm{C}$ less than the first sensor temperature, confirming that gallery temperature was warmer than it was in 1997-1998. More significant, hygrometry was $74 \% \mathrm{RH}$ instead of $55 \% \mathrm{RH}$ measured during the 1997-1998 period (Fig. 6; hygrometer accuracy is $1 \% \mathrm{RH})$.

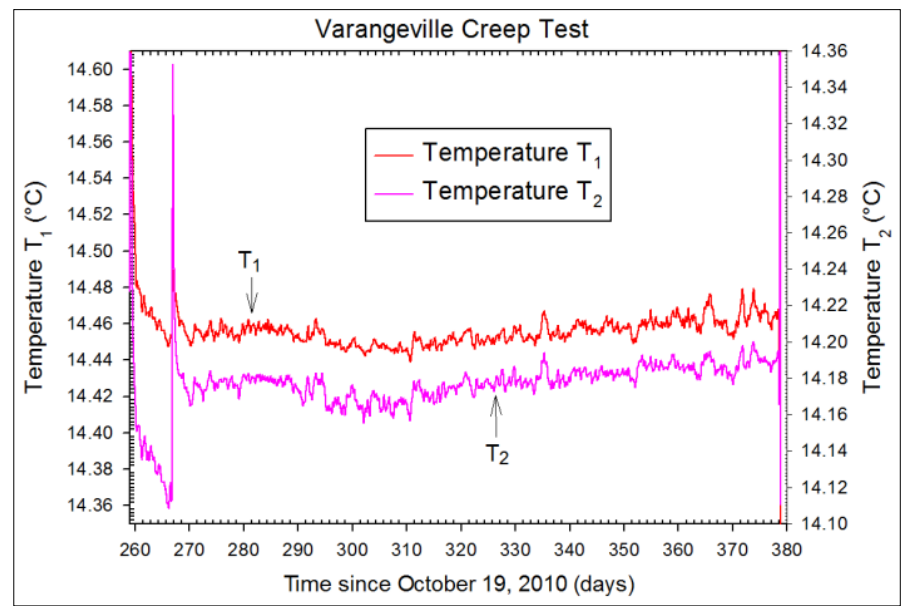


Figure 7. Temperature measured in the gallery days 260-379.

Evidence from other sources pointed to an increase in relative humidity (for instance, a small brine pond had formed close to the gallery entrance). This change can be attributed to modification of the ventilation air path, which is now closer to the gallery entrance than it was several years ago. Such a change in air hygrometry was a concern, as it is known that hygrometry may have a dramatic influence on salt creep rate. From Hunsche \& Schultze (2002), it can be inferred that the creep rate increases by a factor of approximately 5 when \% RH is increased from $55 \%$ to $75 \%$. Because of the hygrometry difference, it was feared that a direct comparison between 1997-1998 and 2010-2011 test results would be difficult.

\section{TEST RESULTS}

\subsection{A test on a Varangéville salt sample}

During the tests, four vertical displacements and two horizontal displacements, together with gallery temperature, hygrometry, and air pressure, are measured every 2 minutes. Figure 8 provides average strains and temperatures measured for the duralumin sample and Varangéville (or CSME) salt specimen.

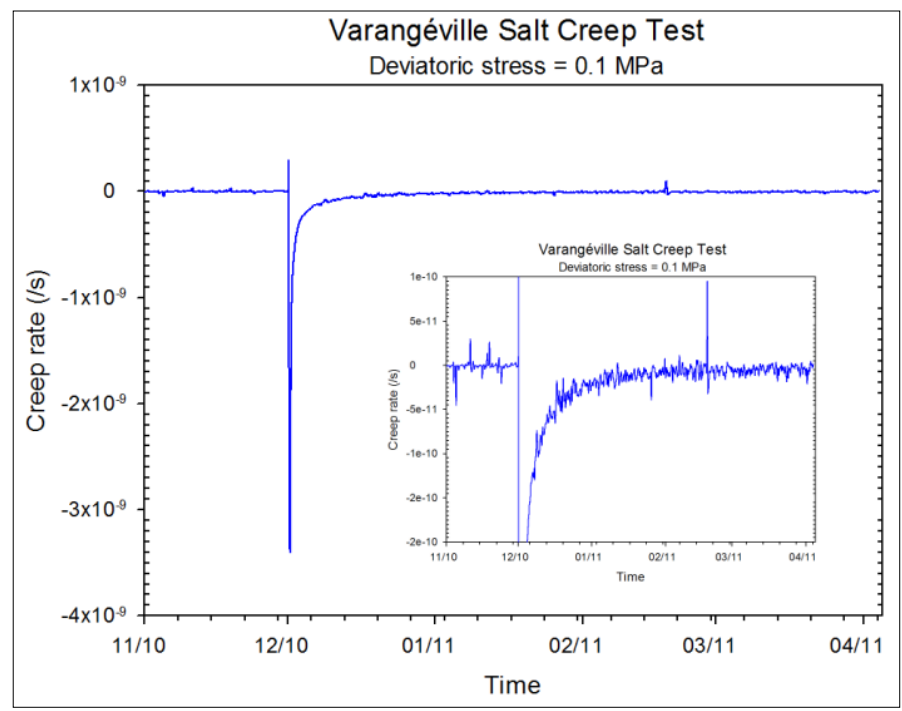

Figure 8. One-month- and 6-month-long creep tests on a duralumin sample and a Varangéville salt sample, respectively.

Figure 9 provides strain and smoothed temperature during a 2-week-long period. On 20 October 2010 (Day 2), the duralumin sample $(D=70 \mathrm{~mm}, H=$ $140 \mathrm{~mm})$ was placed in the creep testing device (duralumin has a low thermal expansion coefficient and is not expected to experience any creep). A 0.15 $\mathrm{MPa}$ axial stress was applied (dead weight was 60 $\mathrm{kg}$ ). One month later, average strains and strain rates were exceedingly small, providing some confidence in the stability of the measurement system (Fig. 8). On 30 November (Day 43), the duralumin sample was replaced with a cylindrical sample of salt from the Varangéville Mine. Varangéville salt contains a fair amount of insolubles. Strain rate as a function of time of this specimen is also presented in Figure 8. Immediately after the load was applied, a transient phase was observed, characterized by fast creep rates (faster than $-3 \times 10^{-9} \mathrm{~s}^{-1}$ ). Six months later, the creep rate had more or less stabilized at approximately $-2.5 \times 10^{-12} \mathrm{~s}^{-1}$. This rate is not much faster than the rate observed during the 1997-1998 test performed on an Etrez salt sample, which was $1.4 \times 10^{-12} \mathrm{~s}^{-1}$. In addition to possible differences between the respective behaviors of the Varangéville and Etrez salts, this small difference in steady-state creep rates, which is not consistent with the drastic change in air humidity, suggests that strain rate might be less sensitive to air humidity when the applied deviatoric stress is small and when no dilation of the sample is expected.

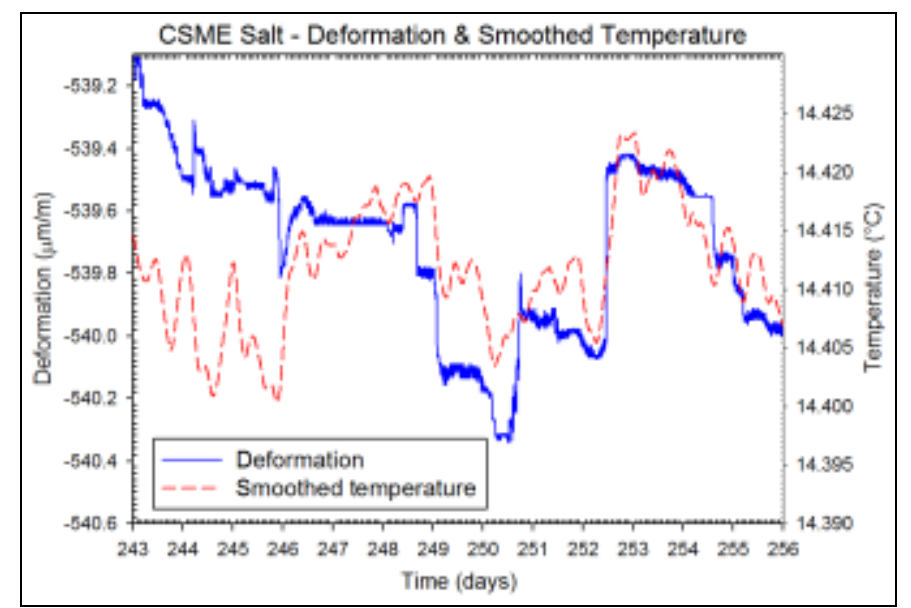

Figure 9. Comparison between deformation of Varangéville salt sample and smoothed temperature.

Strains exhibited large fluctuations, which are clearly correlated with temperature fluctuations (Fig. 9). The empirical correlation coefficient is close to salt thermal expansion coefficient, suggesting that strain fluctuations originate in salt thermoelastic behavior.

\subsection{A test on Avery Island salt and crushed salt samples}

On 11 July 2011, a creep test having an axial load of 0.1 MPa was initiated on an Avery Island salt sample. Avery Island salt creep has been extensively studied by RESPEC (e.g. RE/SPEC Inc., 1987). The results of 55 creep tests performed on Avery Island salt are illustrated in Figure 10. All these tests were not performed according to the most recent techniques; however, they provide a good overall picture of salt behavior over a large range of stress (3.5 to $20 \mathrm{MPa}$ ) and temperature (room temperature to $200^{\circ} \mathrm{C}$ ). These data were fitted against the MunsonDawson constitutive law (Munson 1998) assuming Waste Isolation Pilot Plant (WIPP) salt properties except for parameters $A_{1}, A_{2}$, and $n_{2}$, which are es- 
pecially significant in the range of stress and temperature of interest. Extrapolation of the model at low stress and room temperature suggests that steady-state strain rate should be slower than $-10^{-14}$ $\mathrm{s}^{-1}$.

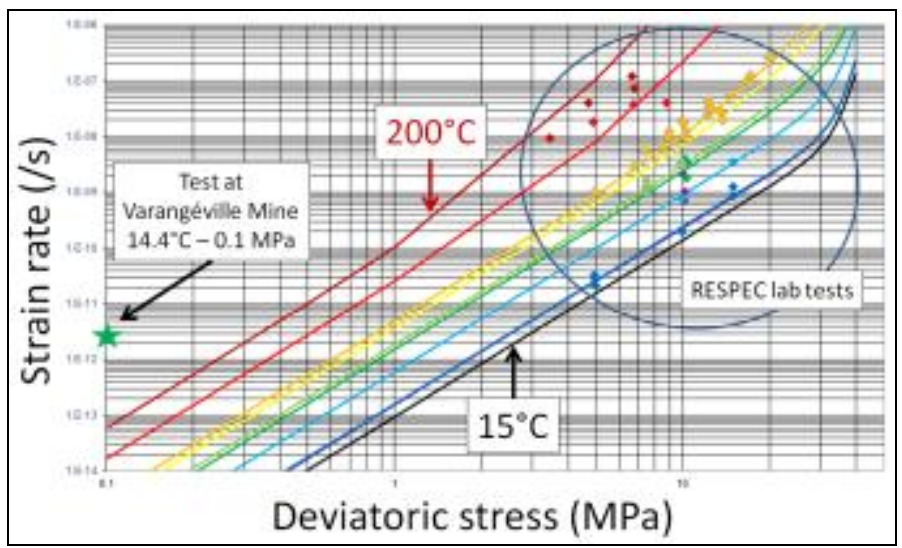

Figure 10. Avery Island salt steady-state strain rate as a function of deviatoric stress and temperature.

At the same time as the Avery Island test was being performed, a second testing device was commissioned in the mine gallery and a test was initiated on a crushed-salt sample. Ten-kg blocks of pure sea salt (Dynavena) were used; these blocks are commercialized for horse feeding. The Dynavena salt is porous (c.a. 10\%) and presents a wide range of grain sizes, between 10-200 micrometers. Cylindrical samples could not be cored correctly from this raw material because integrity was poor as the specimens partly disaggregate during petrol-cooled machining. Therefore, 10-cm-cubic blocks were subjected to hightemperature sintering; that is to say, annealing at $750^{\circ} \mathrm{C}$ (at atmospheric pressure) for a week. This thermal treatment reduced porosity to less than $3 \%$ and strongly improved grain-to-grain bonding and sample integrity. The sintered material allowed for machining of cylindrical cores $4 \mathrm{~cm}$ in diameter and $8 \mathrm{~cm}$ high that were machined carefully and polished to ensure flat and parallel surfaces for axial loading. The synthetic sample was set on a similar device as natural salt samples; however, only three vertical sensors (instead of four during the other tests) were used. The applied load was $0.24 \mathrm{MPa}$.

The axial strains as a function of time are presented in Figure 11. The origin of strain plotted at time equal zero in Figure 11 is the sample strain 2 days after the test began (during the first couple of days of the test, the testing frame was not stable and displacements were erratic). The jump in strain recorded on the $9^{\text {th }}$ day is believed to be caused by a blast of explosives in the mine. After a 2-month-long testing period, steady state was not reached.

Creep rates provided in Figure 12 for Avery Island salt and crushed salt were smoothed through averaging. It was necessary to smooth the data because large fluctuations are experienced if rates are computed based on the 2-minute data collection fre- quency. The crushed-salt strain rate is faster than the Avery Island strain rate, which can be expected, because the applied load is greater $(0.24 \mathrm{MPa}$ compared to $0.1 \mathrm{MPa}$ ). It must be kept in mind that strain rates are difficult to assess, especially at the end of the testing period. Displacement sensor accuracy is $1.25 \times 10^{-8} \mu \mathrm{m}$, or $10^{-7}$ strain on a $14-\mathrm{cm}$-tall sample. Therefore, in principle, a strain rate of $10^{-12} \mathrm{~s}^{-1}$ is the smallest observable strain rate that can be recorded reliably (however, when sample behavior remains consistent during several days, slower rates can be measured).

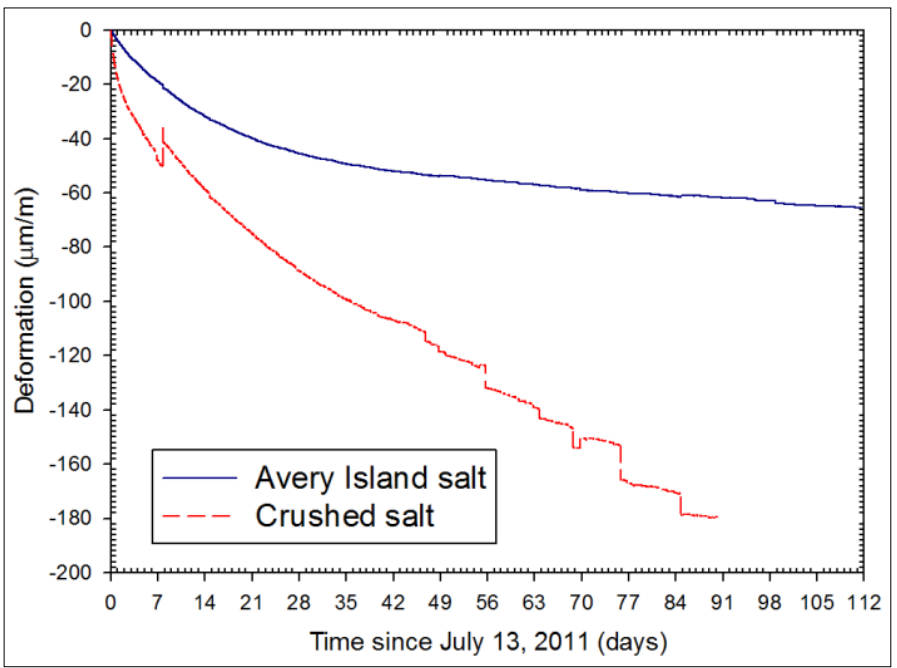

Figure 11. Vertical strain during a 2-month-long creep test on Avery Island salt and crushed-salt samples.

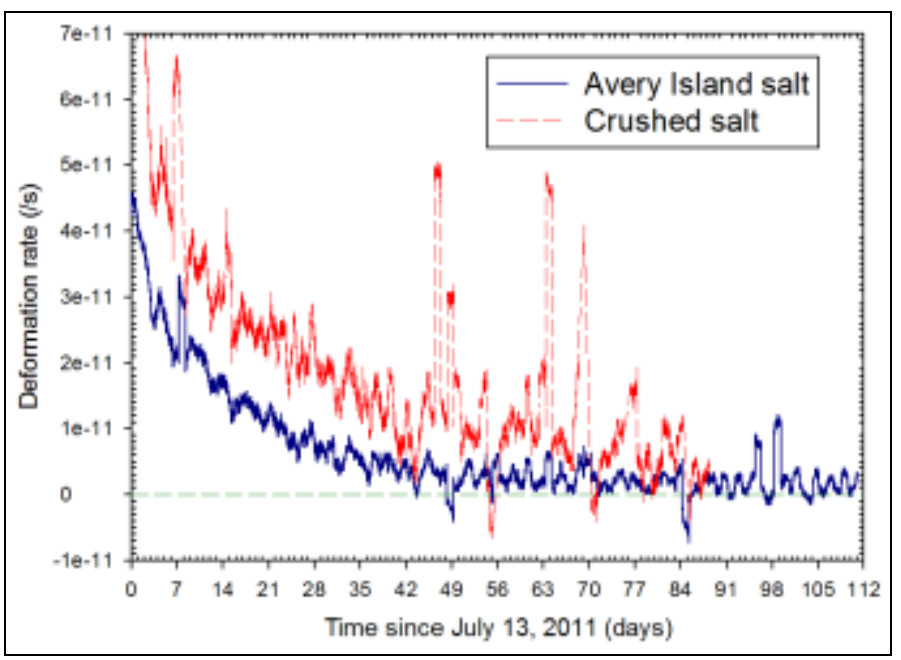

Figure 12. Vertical strain rate during a 2-month-long creep test on Avery Island salt and crushed salt samples.

Even after the smoothing process, temperature and strain rate fluctuations clearly are visible (Fig. 12). They are somewhat correlated, indicating that they have the same origin; as mentioned above, thermal expansion is a good candidate. After 89 days, the creep rate of the crushed-salt sample is approximately $-3.5 \times 10^{-12} \mathrm{~s}^{-1}$ and not fully stabilized; later on, the signals provided by the three sensors became slightly inconsistent (a rotation of the upper plate is suspected). After 112 days, the creep rate of the 
Avery Island salt sample has more or less stabilized; it is about $1.5 \times 10^{-12} \mathrm{~s}^{-1}$. This "steady-state" rate is consistent with that observed during the 1997-1998 tests; i.e. the measured steady-state creep rate of Avery Island salt is much faster than what can be extrapolated from standard creep tests performed under higher deviatoric stress (Fig. 10).

\section{CONCLUSIONS}

The findings at this stage can be summarized as follows.

1 Creep tests were performed in a 160-m-deep room of the Varangéville salt mine where temperature and hygrometry are quite stable. The applied axial load on each salt sample was $0.1 \mathrm{MPa}$ and $0.24 \mathrm{MPa}$ in the case of the crushed-salt sample.

2 After the load is applied, a several-month-long transient creep phase is exhibited.

3 In the case of the Varangéville salt sample, the strain rate observed after 6 months was about $-2.4 \times 10^{-12} \mathrm{~s}^{-1}$. This rate is consistent with the rate observed during earlier tests performed on Etrez salt samples $\left(-1.4 \times 10^{-12} \mathrm{~s}^{-1}\right)$, although relative humidity is much higher now than what it was during the Etrez salt tests, suggesting that this parameter is less influential when the applied stress is relatively small.

4 Tests on Avery Island salt and crushed-salt samples are currently ongoing. The Avery Island salt sample strain rate was about $1.5 \times 10^{-12} \mathrm{~s}^{-1}$ after 112 days. Measured strain rates are consistent with what already has been observed; i.e. the strain rate is much greater than what can be extrapolated from standard creep tests performed under higher deviatoric stress.

\section{ACKNOWLEDGEMENTS}

The authors are indebted to Compagnie des Salins du Midi et Salines de l'Est (CSME) whose kind help has been instrumental, especially to Didier Casanova, Daniel Tribout, Emmanuel Hertz and Cédric Lheur; and to Vincent de Greef, from Ecole Polytechnique - Paris Tech.

\section{REFERENCES}

Banderdt, W.B. \& Sammis, C.G. 1985. Low-Stress hightemperature creep in single crystal $\mathrm{NaCl}$. Phys. Earth Planet. Interiors 41: 108-124.

Bérest, P., Blum, P.A., Charpentier, J.P., Gharbi, H. \& Valès, F. 2005. Very slow creep tests on rock samples. Int. J. Rock Mech. \& Mining Sci. 42: 569-576.
Bérest, P., Brouard, B. \& Karimi-Jafari, M. 2009. The effect of small deviatoric stresses on cavern creep behaviour. Proc $9^{\text {th }}$ World symposium, 574-589. Beijing, ShaZuoliang.

Blum, W. \& Fleischman, C. 1988. On the deformationmechanism map of rock salt. Proc. $2^{\text {nd }}$ Conf. Mech. Beh. of Salt: 7-23. Clausthal-Zellerfeld, Germany: Trans Tech Pub.

Breunesse, J.N., van Eijs, R.M.H.E, de Meer, S. \& Kroon, J.C. 2003. Observation and prediction of the relation between salt creep and land subsidence in solution-mining-The Barradeel case. Proc. SMRI Fall Meeting, Chester: United Kingdom 38-57.

Campos de Orellana, A.J. 1998. Non-Associated pressure solution creep in salt rock mines. Proc. $4^{\text {th }}$ Conf. Mech. Beh. of Salt. 429-444. Clausthal-Zellerfeld, Germany: Trans Tech Pub.

Harper, J. \& Dorn, E. 1957. Viscous creep of aluminium near its melting temperature. Acta Metall. 5: 654-665.

Horseman, S.T. 1988. Moisture content - A major uncertainty in storage cavity closure prediction. Proc. $2^{\text {nd }}$ Conf. Mech. Beh. of Salt. 53-68. Clausthal-Zellerfeld, Germany: Trans Tech Pub.

Hunsche, U. 1988. Measurement of creep in rock salt at small strain rates. Proc. $2^{\text {nd }}$ Conf. Mech. Beh. of Salt: 187-196. Clausthal-Zellerfeld, Germany: Trans Tech Pub.

Hunsche, U \& Schultze, O. 1996. Effect of Humidity and Confining pressure on creep of rock salt. Proc. $3^{\text {rd }}$ Conf. Mech. Beh. of Salt: 237-248. Clausthal-Zellerfeld, Germany: Trans Tech Pub.

Hunsche, U. \& Schultze, O. 2002. Humidity induced creep and its relation to the dilatancy boundary. Proc. $5^{\text {th }}$ Conf. Mech. Beh. of Salt. 73-87. Rotterdam: Balkema.

Kumar, P., Kassner, M.E., Blum, W., Eisenlohr, P. \& Langdon, T.G. 2009. New observations on high-temperature creep at very low stresses. Materials Science and Engineering. A 510-511: 20-24.

Kumar, P., Kassner, M.E. \& Langdon, T.G. 2007. Fifty years of Harper-Dorn creep: a viable creep mechanism or a Californian artifact? J. Mater. Sci. 42: 409-420.

Langer, M. 1984. The rheological behaviour of rock salt.: Proc. $1^{\text {st }}$ Conf. Mech. Beh. of Salt. 201-240. Clausthal-Zellerfeld, Germany: Trans Tech Pub.

Munson, D.E. \& Dawson, P.R. 1984.Salt constitutive modeling using mechanism maps. Proc. $1^{\text {st }}$ Conf. Mech. Beh. of Salt. 717-737. Clausthal-Zellerfeld, Germany: Trans Tech Pub.

Munson, D.E. 1998. Analysis of multistage and other creep data for domal salt. Sandia Report SAND98-2276, October 1998.

RE/SPEC Inc. 1987. Interim evaluation of eight salt viscoplastic laws. RSI-0307. prepared by RE/SPEC Inc., Rapid City, SD, for the Office of Nuclear Waste Isolation, Battelle Memorial Institute, Columbus, $\mathrm{OH}$.

Rokhar, R., Staudtmeister, K. \& Zapf, D. 2011. Rock Mechanical design for a planned gas cavern field in the Preesall project area, Lancashire, UK. Proc. SMRI Fall Meeting. York: 189-203.

Spiers, C.J., Schutjens, P.M.T.M., Brzesowsky, R.H. Peach, C.J., Liezenberg, J.L. \& Zwart, H.J. 1990. Experimental determination of the constitutive parameters governing creep of rocksalt by pressure solution. In Knipe R.J. and Rutter E.H. (eds), Geological Society Special Publication: Deformation Mechanisms, Rheology and Tectonics 54: 215-227.

Uraï, J.L. \& Spiers, C.J. 2007. The effect of grain boundary water on deformation mechanisms and rheology of rocksalt during long-term deformation. Proc. 6th Conf. Mech. Beh. of Salt. 149-158. London: Taylor \& Francis Group.

Wang J.N. \& Nieh T.G. 1995. Effects of the Peierls Stress on the Transition from Power Law Creep to Harper-Dorn Creep. Acta Metallurgica et Materialia, 43(4): 1415-1419. 